\title{
A ESCOLARIZAÇÃO DE JOVENS PRIVADOS DE LIBERDADE NO CENTRO SOCIOEDUCATIVO SANTA JULIANA
}

\author{
THE SCHOOLING OF PRIVATE YOUNGS OF FREEDOM IN THE \\ SANTO JULIAN SOCIOEDUCATIVE CENTER
}

\section{LA ESCOLARIZACIÓN DE JÓVENES PRIVADOS DE LIBERTAD EN EL CENTRO SOCIOEDUCATIVO SANTA JULIANA}

Wilkerson Oliveira de Avilar ${ }^{1}$; Maria Nilvane Fernandes ${ }^{2}$

RESUMO

A preocupação basilar deste estudo é refletir sobre as práticas socioeducativas de jovens privados de liberdade, com destaque para a escolarização como meio de emancipação política dos sujeitos responsabilizados pelo cometimento de atos infracionais. Este artigo tem como objetivo analisar os espaços e as condições em que ocorre o processo formal de ensino-aprendizagem de adolescentes e jovens internados (provisórios e sentenciados) no Centro Socioeducativo Santa Juliana, localizado em Rio Branco, Capital do Estado do Acre, à luz dos parâmetros do Sistema Nacional do Atendimento Socioeducativo (SINASE) e legislações que tratam do tema de forma específica. Para alcançar os objetivos propostos, utilizamos como recurso teórico-metodológico a pesquisa documental com a análise pormenorizada de materiais já publicados na legislação brasileira e estadual e o registro de dados colhidos empiricamente em diário de campo. O recorte temporal da coleta de dados possui como registro os meses de junho a agosto de 2016, por meio do acompanhamento da rotina institucional e da análise de dados fornecidos pela administração da Unidade socioeducativa que é realizada pelo Instituto Socioeducativo (ISE). A análise possibilitou aos pesquisadores concluírem que as condições estruturais e de superlotação impossibilitaram, no período analisado, a garantia de escolarização a todos os internos, contribuindo com a precarização do atendimento socioeducativo e o diagnóstico da violação de direitos fundamentais estabelecidos pelo Estatuto da Criança e do Adolescente.

PALAVRAS-CHAVE: Socioeducação. Adolescente em conflito com a lei. Privação de liberdade. Educação escolar. Educação de Jovens e Adultos.

\section{ABSTRACT}

The main concern of this study is to reflect on the socio-educational practices of young people deprived of their liberty, with emphasis on schooling as a means of political emancipation of the subjects responsible for committing offenses. This article aims to analyze the spaces and conditions under which the formal teachinglearning process of adolescents and young interns (provisional and sentenced) occurs at the Santa Juliana Socio-Educational Center, located in Rio Branco, Capital of the State of Acre, in the light of the parameters of the National System of Socioeducational Care (SINASE) and legislations that deal specifically with the theme. To achieve the proposed objectives we used as a theoretical-methodological resource the documentary research with the detailed analysis of materials already published in the Brazilian and state legislation and the registration of data collected empirically in a field diary. The time frame of data collection is recorded from June to August 2016, through the monitoring of institutional routine and analysis of data provided by the administration of the socio-educational unit that is performed by the Socio-educational Institute (ISE). The analysis allowed the researchers to conclude that the structural and overcrowded conditions made it

\footnotetext{
${ }^{1}$ Mestrando em Educação Profissional e Tecnológica - Instituto Federal do Acre (IFAC). Rio Branco, AC - Brasil. Servidor público - Instituto de Administração Penitenciária do Estado do Acre (IAPEN/AC). Rio Branco, AC Brasil. E-mail: wil.avilar@gmail.com

2 Doutora em Educação - Universidade Estadual de Maringá (UEM). Maringá, PR - Brasil. Professora do Departamento de Teoria e Fundamentos - Universidade Federal do Amazonas (UFAM). Manaus, AM - Brasil.

E-mail: nilvane@gmail.com
}

Submetido em: 15/02/2019 - Aceito em: 25/11/2019

(C) ETD-Educação Temática Digital Campinas, SP $\quad$ v.22 $\quad$ n.2 $\quad$ p. 389-405 abr./jun. 2020


impossible, during the analyzed period, to guarantee schooling for all inmates, contributing to the precariousness of socio-educational care and the diagnosis of the violation of fundamental rights established by the Statute of the Child and the Child. Teenager

KEYWORDS: Socioeducation. Teenager in conflict with the law. Deprivation of liberty. Schooling. Youth and Adult Education.

\section{RESUMEN}

La preocupación básica de este estudio es reflexionar sobre las prácticas socioeducativas de jóvenes privados de libertad, con destaque para la escolarización como medio de emancipación política de los sujetos responsabilizados por la comisión de actos infractores. Este artículo tiene como objetivo analizar los espacios y las condiciones en que ocurre el proceso formal de enseñanza-aprendizaje de adolescentes y jóvenes internados (provisionales y sentenciados) en el Centro Socioeducativo Santa Juliana, ubicado en Rio Branco, Capital del Estado de Acre, a la luz de los parámetros del Sistema Nacional del Atendimiento Socioeducativo (SINASE) y legislaciones que tratan del tema de forma específica. Para alcanzar los objetivos propuestos utilizamos como recurso teórico-metodológico la investigación documental (análisis detallado de materiales ya publicados en la legislación brasileña y estadual), y el registro de los datos recopilados empíricamente en un diario de campo. El recorte temporal de la recolección de datos tiene como registro los meses de junio a agosto de 2016, por medio del seguimiento de la rutina institucional y del análisis de datos proporcionados por la administración de la Unidad socioeducativa que es realizada por el Instituto Socioeducativo (ISE). El análisis posibilitó a los investigadores concluir que las condiciones estructurales y de hacinamiento imposibilitaron en el período analizado la garantía de escolarización a todos los internos, contribuyendo con la precarización de la atención socioeducativa y el diagnóstico de la violación de derechos fundamentales establecidos por el Estatuto del Niño y del adolescente.

PALABRAS CLAVE: Socioeducation. Adolescente en conflicto con la ley. Privación de libertad. Educación escolar. Educación de Jóvenes y Adultos.

\section{INTRODUÇÃO}

O presente artigo analisa o acesso à educação escolar de adolescentes e jovens privados de liberdade no Centro Socioeducativo Santa Juliana ${ }^{3}$. Localizado na Capital Rio Branco, o Centro tem a incumbência de acolher pessoas do gênero masculino, com idade entre 12 a 18 anos (em casos excepcionais, até 21 anos) acusados da prática de atos infracionais e responsabilizados com a aplicação da medida socioeducativa de Internação, o que significa que permanecerão detidos por até três anos, sendo possível que, posteriormente sejam sancionados com outra medida mais branda, como a Semiliberdade, a Liberdade Assistida e a Prestação de Serviços à Comunidade. A Internação em estabelecimento educacional é definida pelo artigo 121 do Estatuto da Criança e do Adolescente (Lei no 8.069, de 13 de julho de 1990). Durante o cumprimento dessa medida, a frequência escolar é obrigatória e deve ser ofertada pelo poder público.

\footnotetext{
${ }^{3} \mathrm{O}$ ordenamento jurídico brasileiro considera adolescente a pessoa com idade entre 12 e 18 anos e jovem a pessoa com idade entres 15 a 29 anos (BRASIL, 1990). Para esse estudo o termo jovem abrangerá, apenas, os indivíduos com idade entre 15 e 21 anos.
} 
Ocorre, entretanto, que vários fatores têm interferido nesse processo, como demonstraremos na análise realizada. O público-alvo da pesquisa é composto, na sua maioria, por jovens com idade entre 16 e 21 anos (83\%), do gênero masculino (96\%), de cor parda e preta (59,08\%), e nível de escolaridade inferior ao da média nacional (BRASIL, 2018). De origem rural ou urbana, envolvidos direta ou indiretamente com álcool e outras drogas, através do uso, abuso ou tráfico de substâncias psicoativas, esses adolescentes estigmatizados como delinquentes, desajustados ou simplesmente, menores infratores ${ }^{4}$, uma vez envolvidos com a prática de ato infracional, quando responsabilizados; são sancionados com uma das medidas socioeducativas estabelecidas pela legislação vigente que, segundo a Lei no $12.594 / 2012$, têm por objetivos ${ }^{5}$ :

I a responsabilização do adolescente/jovem quanto às consequências lesivas do ato infracional, sempre que possível incentivando a sua reparação;

II a integração social do adolescente/jovem e a garantia de seus direitos individuais e sociais, por meio do cumprimento de seu plano individual de atendimento; e

III a desaprovação da conduta infracional, efetivando as disposições da sentença como parâmetro máximo de privação de liberdade ou restrição de direitos, observados os limites previstos em lei (BRASIL, 2012, p. 1, Art. 1으 § 2).

Portanto, durante o cumprimento da medida, esses sujeitos devem passar por um rigoroso processo de formação, de maneira a prepará-los para a sua emancipação política, afastá-los da prática de delitos e contribuir para a superação da distorção idade-série ${ }^{6}$. Contudo, o que se observa no Centro Socioeducativo Santa Juliana é o agravamento dessa condição, visto que poucos internos frequentam a escolarização e uma parcela ínfima é inserida em cursos profissionalizantes. Consequentemente, quando são desinternados, poucos estão preparados para um afastamento da condição de conflitualidade e a ingressar no mundo do trabalho.

Portanto, o objetivo primordial desse estudo é, à luz dos parâmetros do Sistema Nacional de Atendimento Socioeducativa (SINASE), analisar os espaços e as condições em

\footnotetext{
${ }^{4} \mathrm{~A}$ utilização do termo menor e outros termos correlatos neste artigo segue a orientação do tempo histórico em que eram utilizados. Convém mencionar, entretanto, que os autores possuem consciência da utilização adequada de termos politicamente corretos.

${ }^{5} \mathrm{O}$ Estatuto da Criança e do Adolescente define seis sanções aplicadas aos adolescentes e jovens acusados da prática de ato infracional, a saber: Advertência; Obrigação de Reparar o Dano; Prestação de Serviço à Comunidade; Liberdade Assistida; Semiliberdade e Internação (BRASIL, 1990, Art. 112).

6 "É a condição em que se encontra o aluno que está cursando uma série com idade superior a que seria recomendada ou prevista. É também denominada Defasagem Idade-Série. O valor da distorção é calculado em anos e representa a defasagem entre a idade do aluno e a idade recomendada para a série que ele está cursando. $O$ aluno é considerado em situação de distorção ou defasagem idade-série quando a diferença entre a idade do aluno e a idade prevista para a série é de dois anos ou mais. A situação de distorção pode ser desencadeada por três fatores principais: a repetência; a entrada tardia na escola; abandono e retorno do aluno evadido" (SARAIVA, 2010, p. 1).
} 
que ocorre o processo formal de ensino-aprendizagem de adolescentes e jovens internados (provisórios e sentenciados) no Centro Socioeducativo Santa Juliana.

Para alcançar o objetivo proposto, utilizou-se como recurso teórico-metodológico a pesquisa documental, uma vez que foram analisadas legislações específicas, como: Constituição da República Federativa do Brasil (1988); Estatuto da Criança e do Adolescente (1990); Lei de Diretrizes e Bases da Educação Nacional (1996); Resolução no 119, homologada pelo Conselho Nacional dos Direitos da Criança e do Adolescente (CONANDA) e Lei no 12.594/2012, entre outras. Por fim, produzimos dados empíricos coletados durante a observação da rotina institucional realizada durante o período de junho a agosto de 2016.

As visitas ocorreram em dias e horários alternados (em média duas vezes por semana) com o objetivo de analisar a rotina institucional de cada plantão. As informações coletadas foram registradas em diário de campo que foi utilizado pelo pesquisador que atuava como agente de segurança socioeducativo na instituição. Atendendo aos cuidados éticos exigidos na investigação em instituições, a coleta dos dados foi autorizada pela direção do Centro Socioeducativo Santa Juliana.

Segundo Lima, Mioto e Dal Prá (2007), a documentação é um elemento constitutivo da ação profissional, uma vez que dá materialidade ao comprovar a realização da ação, em fichas, prontuários, relatórios de atendimentos realizados em instituições ou em domicílios, dentre outros. Nesse aspecto, o pesquisador coletou informações utilizando tais procedimentos. Portanto, uma pesquisa documental não é aquela realizada, exclusivamente, em documentos históricos, possuindo, por assim dizer, um caráter dinâmico e flexível. Para tanto, o pesquisador registrou datas, horários e informações coletadas com outras informações que eram importantes para o registro memorial e documental.

\section{OS LIMITES DA EXECUÇÃO DAS MEDIDAS SOCIOEDUCATIVAS NO ACRE}

O prédio onde atualmente está instalado o Centro Socioeducativo Santa Juliana (CSSJ) foi inaugurado em 1979, época da promulgação do segundo Código de Menores (Lei no 6.697/1979), período de reafirmação da Doutrina da Situação Irregular e prevalência do modelo assistencialista de atendimento. Nessa ocasião, foi instituída em Rio Branco a Divisão de Segurança e Proteção ao Menor (DSPM), que, depois, passou a se chamar, pejorativamente, de Pousada do Menor, sob a competência da então Fundação do Bem Estar Social do Acre (FUNBESA), incumbida de abrigar menores infratores do gênero masculino.

Quase dez anos depois, foi promulgada a nova Constituição Federal do Brasil (1988), instituindo, através do artigo 227, um sistema especial de proteção para a população infanto-juvenil. Em 1990, a promulgação do Estatuto da Criança e do Adolescente criou

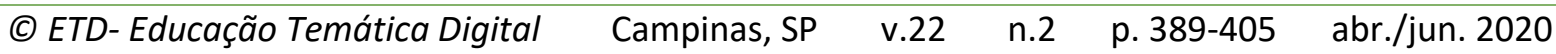


condições de exigibilidade para os direitos do público em questão, referenciados em todas as demais leis que tratam dessa parcela da população brasileira (COSTA, 2008).

Nessa época, no Acre, os programas de atendimento socioeducativo em meio fechado (Semiliberdade e Internação e, de forma excepcional, a Liberdade Assistida) passaram a ser administrados pela Secretaria de Estado de Cidadania e Assistência Social (SECIAS), permanecendo sob os domínios da assistência social até 2008, quando foi criada a Secretaria de Estado Extraordinária de Ação Socioeducativa (SEAS). Contudo, onze meses depois, a SEAS foi extinta em detrimento da criação do Instituto Socioeducativo do Estado do Acre (ISE), instituído por meio da Lei no 2.111, de 31 de dezembro de 2008.

Com a incumbência de promover um atendimento regionalizado, o ISE passou a cobrir todo o território do Acre, através de unidades de atendimento implantadas em cada Regional ${ }^{7}$. Durante a primeira gestão, que durou de 2009 a 2010, foi publicada a Portaria no 84, de 25 de outubro de 2010, dispondo as nomenclaturas e designações do Centro Socioeducativo Santa Juliana (CSSJ) e demais unidades de atendimento do Estado ${ }^{8}$.

Ao longo desse período, especificamente, entre os anos de 1979 a 2008, o prédio passou por várias reformas, incluindo alterações e ampliação estrutural, visando, entre outras coisas, adequar os espaços às exigências do atendimento socioeducativo. Mesmo assim, existe um distanciamento dos padrões arquitetônicos estabelecidos pelo SINASE (CONANDA, 2006), que os deixam assemelhados às casas de detenção destinadas aos presos adultos.

Conforme a Portaria no 203, de 11 de dezembro de 2013, o CSSJ possui capacidade para receber 59 adolescentes e jovens, entre provisórios e sentenciados. Todavia chega a acolher o triplo desse contingente ${ }^{9}$. Segundo informações cedidas pela administração da própria Unidade, em 28 de novembro de 2016, o número de adolescentes e jovens, nesta data era de 157, dentre os quais: 116 estavam sentenciados, dois cumpriam internação sanção e 39 estavam sob Internação Provisória. Desse efetivo, apenas 46 alunos frequentavam a escolarização, ou melhor, $29,2 \%$ dos internos.

Além disso, outros fatores dificultam a realização de uma metodologia de trabalho voltada para a emancipação desses sujeitos, a saber: a insuficiência de servidores; a precariedade das instalações físicas; a ausência de alguns documentos institucionais que influenciam no desenvolvimento da proposta pedagógica; a centralidade das ações de

\footnotetext{
${ }^{7}$ Regionais do Alto e Baixo Acre: CS Santa Juliana, CS Aquiry, CS Acre e CS Mocinha Magalhães, localizados na Cidade de Rio Branco; Regional do Purus: CS Purus, localizado na Cidade de Sena Madureira; Regional Tarauacá/Envira: CS Feijó, localizado na Cidade de Feijó; Regional do Juruá: CS Juruá, Localizado na Cidade de Cruzeiro do Sul.

8 Publicado no Diário Oficial do Estado (DOE) sob no 10.409, de 27 de outubro de 2010.

${ }^{9}$ Publicada no DOE no 11.199, em 13 de dezembro de 2013.
}

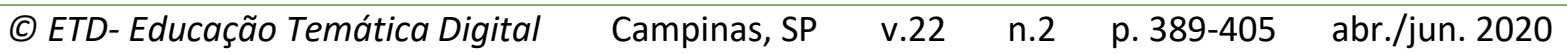


segurança e a violação de alguns direitos básicos.

A insuficiência de servidores e funcionários ante o efetivo de internos e a ausência de alguns profissionais na composição da equipe multidisciplinar é um dos problemas enfrentados para a execução de uma proposta pedagógica adequada. O SINASE estabeleceu que a equipe mínima para executar a medida socioeducativa de internação de até 40 internos, e que deve ser composta por um diretor; um coordenador técnico; dois assistentes sociais; dois psicólogos; um pedagogo; um advogado e agentes socioeducativos, bem como demais profissionais necessários para o desenvolvimento de saúde, escolarização, esporte, cultura, lazer, profissionalização e administração (CONANDA, 2006).

Em relação ao número mínimo de agentes socioeducativos, o documento normativo do SINASE recomendou que fosse considerada a dinâmica institucional, as ausências por gozo de férias, licenças, afastamentos e o perfil do socioeducando, podendo ocorrer uma relação numérica de dois agentes socioeducativos para cada adolescente ou jovem até um agente socioeducativo para cinco adolescente ou jovem (CONANDA, 2006).

De acordo com a administração do CSSJ, o quadro de servidores/funcionários é composto por: um diretor; três coordenadores (sendo um de Segurança, um Técnico e um Pedagógico); um Auxiliar Administrativo; um Auxiliar Técnico; quatro Assistentes Sociais; uma Psicóloga; 13 professores (sendo três de Ciências Humanas, três de Ciências da Natureza, três de Linguagens e Códigos, dois de Ciências Exatas e dois de Educação Física); 45 Agentes Socioeducativos (distribuídos em quatro plantões); um motorista; três Agentes de Apoio (lavanderia, rouparia e limpeza).

A partir dos dados acima, é possível constatar o quanto a equipe do CSSJ está defasada. Considerando o efetivo de internos dos últimos três anos, que oscilou entre 120 e 170, verifica-se que a equipe atual é, em média, três vezes menor que a equipe mínima recomendada no SINASE (CONANDA, 2006). Além disso, podemos constatar a ausência de alguns profissionais necessários à composição da equipe multidisciplinar, como pedagogos e advogados.

A precariedade das instalações físicas dos alojamentos pode ser observada por uma série de fatores observados, como pelo número de infiltrações de água nas paredes, que contribuem para a proliferação de fungos; pelo aparecimento de baratas e outros insetos oportunistas e pelo constante mau cheiro, típicos de ambientes insalubres. Os colchões e uniformes são constantemente reaproveitados, portanto, encontram-se esgarçados e, na maioria das vezes, são insuficientes para todos os internos. De forma semelhante, o fornecimento de materiais básicos como produtos de higiene pessoal, toalhas de banho, lençóis de cama, chinelos etc., não é regular, por isso, boa parte deles é fornecida pelos familiares dos internos. O mesmo acontece com materiais de insumo e consumo, o que viola o direito dos adolescentes e jovens de conviverem em um ambiente digno e humanizado.

\begin{tabular}{|c|c|}
\hline - Educação Temática Digital & $v 22$ \\
\hline
\end{tabular}


A real condição de habitabilidade somada à insuficiência de produtos básicos interfere diretamente na saúde física e mental dos socioeducandos, além de violar diretamente o exposto no artigo 94 do Estatuto da Criança e do Adolescente:

As entidades que desenvolvem programas de internação têm as seguintes obrigações, entre outras:

III oferecer atendimento personalizado, em pequenas unidades e grupos reduzidos; [...];

IV preservar a identidade e oferecer ambiente de respeito e dignidade ao adolescente; [...];

VII oferecer instalações físicas em condições adequadas de habitabilidade, higiene, salubridade e segurança e os objetos necessários à higiene pessoal;

VIII oferecer vestuário e alimentação suficientes e adequados à faixa etária dos adolescentes atendidos;

IX oferecer cuidados médicos, psicológicos, odontológicos e farmacêuticos (BRASIL, 1990, Art. 94).

A inexistência de proposta pedagógica e regimento interno que oriente o trabalho socioeducativo e as ações dos servidores, respectivamente, viola uma das diretrizes do atendimento aos adolescentes e jovens, visto que o CONANDA (2006, p. 47) estabelece como uma das diretrizes a obrigatoriedade da construção de um "projeto pedagógico claro e escrito em consonância com os princípios do SINASE", considerando-se que o referido projeto deve ser "[...] orientador na elaboração dos demais documentos institucionais (regimento interno, normas disciplinares, plano individual de atendimento)" (CONANDA, 2006, p. 47). Além disso, é um agravante o não registro do Programa de Atendimento (Internação) junto ao Conselho Municipal dos Direitos da Criança e Adolescente (CMDCA), sendo essa uma exigência expressa no parágrafo único do artigo 90, do Estatuto (BRASIL, 1990). O Estado também não avançou na organização de um sistema informatizado que possa salvar as informações do fluxo de internos e egressos. Por falta de equipamentos e interesse da gestão, o Sistema para a Infância e Adolescência (SIPIA) ou SIPIA/SINASE não foi implementado no estado do Acre, e, mesmo tendo algumas iniciativas muito tímidas, ao longo das quatro gestões, nenhuma delas se efetivou de fato, o que traz enormes prejuízos no âmbito da gestão, da pesquisa e da execução da medida socioeducativa ${ }^{10}$.

10 O Sistema Nacional de Acompanhamento de Medidas Socioeducativas é uma versão Web Nacional integrada ao SIPIA, portanto, denominado SIPIA/SINASE. Tal Sistema propõe a implementação de um Sistema de Informação em rede para registro e tratamento de dados referentes aos adolescentes em conflito com a lei. O Sistema possuía abrangência nacional, banco de dados único e todos os operadores de direitos o utilizavam em rede, de maneira a ser ferramenta de integração entre as instituições executoras de medidas socioeducativas: Ministério público, Varas da Infância e Juventude, Centros de Referência Especializada da Assistência Social (CREAS) e demais órgãos das esferas municipal, estadual e federal (BRASIL, 2019). 
Além disso, a gestão das unidades de atendimento possui uma rotina institucional que possui foco na segurança, isto é, toda atividade desenvolvida com os adolescentes e jovens necessita da anuência do setor de segurança para que seja realizada. Não se descarta, aqui, a importância desse departamento, muito menos a sua submissão às ações pedagógicas, mas se defende uma segurança estratégica que atue dentro da legalidade e na proporcionalidade de cada evento. Contudo, o que se observa no cotidiano do CSSJ é a elevação desproporcional de determinados procedimentos (revistas pessoais excessivas; condução interna com o uso de algemas; tratamento degradante etc.) e a banalização de certos equipamentos de uso restrito (posse constante de tonfas; uso de escudos na hora de movimentar os internos, sem fundado receio de ocorrência etc.).

Destaca-se, ainda, o despreparo de certos profissionais na lida com o público atendido. Em alguns casos, com o intuito de alcançar os objetivos de manutenção da ordem e disciplina, surgem situações nas quais o servidor utiliza do autoritarismo, xingamento, agressões verbais, violência psicológica e, em casos extremos, até física. Esse tipo de conduta alimenta uma cultura de ódio entre os envolvidos, rivalizando um relacionamento que deveria ser de interação, de referência, obstante os princípios e diretrizes do atendimento socioeducativo.

A falta de suporte do Estado promove também constantes violações de direitos básicos por quem deveria assegurar e promover os direitos fundamentais daqueles que estão sob sua tutela. Entre as principais violações, destacam-se aquelas relacionadas ao desenvolvimento pessoal e social do indivíduo, ou seja, o acesso ao direito à educação, à cultura, ao esporte, ao lazer e à profissionalização. Portanto, como estas infrações estão diretamente relacionadas à política de escolarização, ora objeto desse estudo, faz-se necessário abordar o contexto de sua implantação nas medidas socioeducativas, no âmbito do ISE.

\section{A ESCOLARIZAÇÃO DOS ADOLESCENTES PRIVADOS DE LIBERDADE NO ACRE}

A escolarização no CSSJ, assim como nas demais Unidades de atendimento do estado do Acre, é oferecida por meio da parceria entre o ISE e a Secretaria de Estado de Educação e Esporte (SEE). Para concretizar o processo, o Estado criou a Escola Darquinho, para ser a responsável pela oferta e administração dos núcleos de escolarização no âmbito do ISE, tornando-a encarregada pela "[...] implantação e implementação da oferta de educação básica e responsável pela escrituração escolar [...]" (ACRE, 2008, p. 1) $)^{11}$.

\footnotetext{
${ }^{11}$ A Escola Darquinho foi criada por meio do Decreto no 3.558, de 18 de novembro de 2008 - publicado no DOE no 9.933. Segundo a Portaria no 1.646 emitida pela SEE/AC em 4 de maio de 2011, a Escola construída nas dependências do Centro Socioeducativo Acre passou a ser denominada Centro de Referência Socioeducativo 'Darquinho' (ACRE, 2008).
} 
Contudo, a regulamentação da Escola vem acontecendo de forma gradativa. Em 2011, a Portaria no 1.646, de 04 de maio de 2011, autorizou a oferta da Educação Básica, por intermédio dos programas de aceleração da aprendizagem: Educação de Jovens e Adultos (EJA) e o Programa Especial de Ensino Médio (PEEM). Em 2014, o Conselho Estadual de Educação (CEE) emitiu a Resolução no 267/2014, que dispunha sobre a oferta de ensino regular para alunos em contexto socioeducativo.

Conforme estabelecido pela mencionada Resolução, o Centro de Referência Socioeducativo Darquinho (CRES/Darquinho) é o responsável por implantar e implementar a oferta de Educação Básica, responder "[...] pela escrituração escolar (matrícula, transferência, expedição de histórico e arquivamento de documentação), oriunda dos espaços anexos instalados em todas as unidades socioeducativas do Estado do Acre" (ACRE, 2015, p. 7).

A SEE, como Secretaria parceira, "[...] deve prover as instalações, equipamentos e os profissionais adequados ao pleno funcionamento dessa instituição educativa e nas salas anexas, de modo a que atenda aos requisitos exigidos para o credenciamento da unidade", além de viabilizar "[...] dotação de recursos financeiros para a aquisição de uniformes escolares e livros didáticos aos alunos" (ACRE, 2015, p. 7). Vale ressaltar que, no caso específico dos adolescentes que participam da escolarização no CSSJ, eles não usam uniformes escolares, vão para aula com as vestimentas padrão da Unidade. Além disso, garantir aos professores e demais profissionais da Educação materiais didáticos e tecnológicos, bem como, formação inicial e continuada.

No âmbito da formação escolar dos adolescentes ou na organização didáticopedagógica e curricular, a Lei orienta viabilizar para cada modalidade da Educação Básica:

\footnotetext{
I análise do percurso escolar de cada educando;

Il tempo de permanência do aluno;

III flexibilidade curricular [...];

V jornada de tempo integral para o desenvolvimento da proposta pedagógica, a fim de contemplar a Educação Básica e Educação Profissional

VI avaliação cujos resultados sejam codificados em relatórios descritivos, visualizando o desenvolvimento das capacidades, habilidades alcançadas por cada aluno; e

VII a necessidade de um currículo que seja integrado e integrador, de forma que as atividades da escola e dos centros (centros de referência ou centros socioeducativos) não sejam concorrentes, mas complementares e que estas atividades sejam pensadas como partes integrantes do currículo (ACRE, 2015, p. 7).
}

Ou seja, enquanto a parte da organização escolar ficou sob a ciência e orientação da SEE, a organização estrutural se manteve sob a responsabilidade do ISE, visto que o artigo 40 da Resolução estabeleceu que o CRES/Darquinho deve garantir:

(C) ETD-Educação Temática Digital Campinas, SP $\quad$ v.22 $\quad$ n.2 $\quad$ p. 389-405 abr./jun. 2020


I instalações adequadas de salas de aulas, laboratório de ciências, biblioteca, sala de arquivo, cozinha adequada e equipada para o fornecimento da merenda escolar e os espaços adequados para a prática de esporte;

II salas anexas equipadas e com boa iluminação, e uma minibiblioteca;

III quadro docente organizado por áreas de conhecimento e multidisciplinar, de forma que atenda às peculiaridades e às especificidades do desenvolvimento do currículo e da proposta pedagógica, para atender a escola Centro e as salas anexas;

IV coordenador e pedagogo que deem conta da demanda da matrícula, do planejamento das atividades e da avaliação da aprendizagem na escola Centro e nos anexos em todo o Estado do Acre;

$\checkmark$ recursos humanos - socioeducadores, na relação especificada pelo SINASE, devidamente capacitado e integrado às ações da educação para prestar proteção, apoio aos docentes, no exercício de suas funções e manutenção da ordem;

VI capacitação, anual ou semestral dos profissionais que atuam nas unidades do sistema socioeducativo de forma a integrar toda a equipe (coordenador, equipe técnica e socioeducadores) com as ações educacionais desenvolvida na unidade e vice-versa (ACRE, 2015, p. 7).

Pouca coisa mudou depois da data de publicação da referida resolução. Os pontos acima elencados até a presente data não foram concretizados no CSSJ. Ao contrário, em 2016, quando iniciaram os conflitos entre faç̧ões criminosas, tudo ficou mais difícil no interior do centro. A segurança tornou-se o principal eixo de ação, e, para garantir a incolumidade de todos, a gestão superior (ISE) viabilizou a separação dos internos por grupos faccionados, o que dificultou ainda mais a inserção na escola, uma vez que alunos de faç̧ões rivais não poderiam mais conviver no mesmo espaço.

A proposta curricular garante que o agrupamento de alunos não seja seriado e seja organizado com base na idade, no contexto histórico dos alunos, no nível de competências e habilidades alcançados nos processos de classificação, na oferta de formação profissional, entre outros critérios. Além disso, a Resolução estabeleceu o prazo de um ano para que o CRES/Darquinho fizesse o credenciamento por meio de um processo que contivesse: 
a) Projeto Político Pedagógico devidamente orientado com base na Indicação CEE/AC n.o 01/2010 e nas orientações constantes da presente resolução;

b) Plano Curricular que dê conta da oferta com qualidade da Educação Básica, níveis e modalidades de ensino e Educação Profissional, levando em consideração o perfil da clientela e as orientações da presente Resolução;

c) O Regimento Interno entendido como código ético que discipline as ações pactuadas nas relações, os direitos e deveres do conjunto de participantes do Centro de Referência Socioeducativo 'Darquinho' e sob sua responsabilidade as salas anexas;

d) Plano Institucional do Centro de Referência Socioeducativo 'Darquinho', responsável pela coordenação e oferta da educação nas salas anexas, estabelecendo as competências, compromissos e responsabilidades;

e) Calendário letivo adequado as necessidades das Unidades socioeducativas, assegurando atividades educacionais durante o ano todo, resguardado o direito trabalhista do professor (ACRE, 2015, p. 7).

O CRES/Darquinho ainda em 2015 conseguiu produzir seu PPP, todavia, os demais documentos ainda estão pendentes.

Nessa conjuntura, o espaço escolar do CSSJ funciona como uma extensão da Escola Darquinho, composto por, apenas, cinco salas de aulas, e atende somente alunos com idade entre 15 e 21 anos, ou seja, a escolarização na unidade contempla, apenas, jovens sentenciados que apresentam defasagem entre idade e ano escolar, obstante as diretrizes dos programas de aceleração.

Novos alunos são inseridos somente no início de cada semestre. Havendo vagas, os adolescentes e jovens que, em atendimento técnico (com a Psicóloga ou as Assistentes Sociais), manifestarem interesse em frequentar a escola são priorizados, o que significa uma violação dos direitos dos jovens à escolarização, visto que o Estatuto determina a realização dessa atividade no âmbito do cumprimento da medida socioeducativa, ainda que eles tenham maioridade civil. Apesar disso, antes de efetivar a matrícula, o Coordenador de Segurança deve aceitar a inserção, sendo que o critério para tal é o comportamento institucional. Convém mencionar que ainda que pareça um privilégio frequentar a escola nessas condições, por falta de incentivo e orientação adequada, a evasão escolar ainda é uma realidade, o que é uma contradição, visto que os estudantes estão privados de liberdade.

Apesar de a escola ser regulamentada para oferecer ensino regular, como mencionado anteriormente, a proposta não se efetivou na prática. Os adolescentes e jovens que ingressam no CSSJ em idade escolar (sem apresentar defasagem de idade/ano escolar) não são inseridos na escolarização devido à idade mínima exigida pelos programas de aceleração da aprendizagem: 15 anos para o Ensino Fundamental e 17 anos para o Ensino 
Médio. O mesmo acontece com os adolescentes/jovens em Internação Provisória ${ }^{12}$, já que existia um projeto específico para esse público, denominado de Projeto de Educação e Cidadania (PEC), que deixou de ser ofertado em $2013^{13}$.

Dessa forma, onde deveria ser um local de inclusão acaba por marginalizar ainda mais aqueles que, por algum motivo, não demonstraram interesse ou possuem um comportamento em desacordo com o exigido pela Unidade. Essa decisão contraria o pressuposto constitucional que declara ser a educação direito de todos e dever do Estado, principalmente quando os sujeitos que possuem esse direito estão sob a sua tutela (BRASIL, 1988, Art. 205). Assim, o Estatuto garantiu esse direito ao afirmar que crianças, adolescentes e jovens:

[...] têm direito à educação, visando ao pleno desenvolvimento de sua pessoa, preparo para o exercício da cidadania e qualificação para o trabalho, assegurandose-Ihes: I igualdade de condições para o acesso e permanência na escola (BRASIL, 1990, Art. 53, inciso I).

A dinâmica escolar no CSSJ é realizada em dois turnos, de segunda a sexta-feira, das 8 às 11 horas e das 14 às 17 horas. Nesse tempo são ofertados Programas de Aceleração da Aprendizagem. O Ensino Fundamental é garantido por meio da Educação de Jovens e Adultos (EJA) e o Ensino Médio, mediante o Programa Especial do Ensino Médio (PEEM).

Aos sábados, de forma quinzenal, é realizado o planejamento pedagógico, sendo alternadamente, vertical e horizontal. O primeiro acontece quando todos os professores, da mesma disciplina, reúnem-se para discutir e definir os conteúdos a serem retomados ou priorizados. Já o segundo, é o momento em que os docentes das diversas disciplinas, que atuam nas medidas socioeducativas, reúnem-se para planejar as ações que deverão ser desenvolvidas nos Centros.

Ambos os programas de ensino supracitados são destinados aos jovens e adultos, com a finalidade de corrigir distorção de idade/série e promover a equidade. Para sanar certas lacunas, é necessário ter um planejamento mais flexível, considerando as peculiaridades de cada Unidade de atendimento, mas sem distanciar-se da realidade escolar extramuros. Apesar disso, a proposta desconsidera o percurso individual de cada jovem que, por sua vez, possuem avanços e dificuldades diferenciadas.

12 Trata-se de medida cautelar baseada em indícios suficientes de autoria e materialidade e pode ser determinada pelo prazo máximo de 45 dias (BRASIL, 1990, Art. 108).

${ }^{13}$ Tal proposta foi construída pelo Centro de Estudo e Pesquisa em Educação e Cidadania (CENPEC), de São Paulo, e implantado no CSSJ, ainda sob a gerência da SECIAS, em 2005. A proposta garantia a oferta de oficinas nos seguintes módulos Educação Ponte para o Mundo, Famílias e Relações Sociais, Justiça e Cidadania, Saúde uma Questão de Cidadania e O Trabalho em Nossas Vidas. Tais módulos orientavam-se em conteúdos transversais sustentados nos debates sobre ética, cidadania e identidade (ACRE, 2006).

(C) ETD-Educação Temática Digital Campinas, SP $\quad$ v.22 $\quad$ n.2 $\quad$ p. 389-405 abr./jun. 2020 
Pensando em contemplar todos os adolescentes e jovens em privação de liberdade, a SEE está desenvolvendo uma proposta específica para as medidas socioeducativas. Segundo informações da direção do CRES/Darquinho, a metodologia de ensino possuirá semelhanças com a proposta do Programa Nacional de Inclusão de Jovens (PROJOVEM), com previsão de implementação para o primeiro semestre de 2017, o que não ocorreu até a presente data. Contudo, destaca-se a falta de profissionais do ISE no processo de elaboração da referida proposta, especialmente porque os Centros Socioeducativos não possuem Pedagogo técnico nas equipes multidisciplinares.

Nesse aspecto, ao abordar sobre o assunto, Zanella (2016) chama atenção para algumas entidades que buscam criar propostas de ensino específicas para determinado tipo de medida socioeducativa. Para tanto, alerta que “Essas propostas 'não possuem' conexão com o conhecimento transmitido pelas escolas, o que dificulta ainda mais a reinserção desses adolescentes no espaço educacional após o cumprimento da medida" (ZANELLA, 2016, p. 178, grifo do autor), o que pode acontecer em qualquer momento, dificultando a continuidade dos estudos que, por vezes, contribuem para a evasão escolar.

Ainda que as aulas sejam planejadas e os professores busquem metodologias atrativas, às vezes, usando recursos a suas próprias expensas, elas não são suficientes para garantir um ensino de qualidade. Entre os fatores de distração destaca-se a disposição das salas de aula, situadas em frente as Alas " $E$ " e " $A$ ", ambas reservadas aos internos de comportamentos subversivos. E quando há princípio de crise, as aulas são imediatamente suspensas e os professores, liberados.

Outro fator diz respeito à falta de banheiro no espaço escolar, o que dificulta a retirada e a condução dos alunos até o banheiro mais próximo, na hora de realizar suas necessidades fisiológicas. Para tanto, é necessário mobilizar certo número de agentes para abrir a porta da sala de aula e inibir possíveis tentativas de fugas em massa, através da técnica denominada de cavalo doido ${ }^{14}$. Assim, a constante circulação de pessoas em frente à escola tira a concentração dos alunos, dificultando o processo de ensino/aprendizagem.

Para se compreender o problema, convém mencionar que, até pouco tempo, o acesso ao prédio do Juizado da Infância e Juventude (JIJ) era realizado através da primeira sala do espaço escolar. Para tanto, solicitava-se que os alunos fossem para o fundo da sala, enquanto um dos agentes abria a porta da sala de aula que dava acesso ao prédio da Vara da Infância e Juventude (VIJ), momento em que o outro agente conduzia o adolescente/jovem ao seu destino (Juizado, Ministério Público ou Defensoria), o que, obviamente, trazia

\footnotetext{
${ }^{14}$ Tal estratégia consiste em agrupar o maior número de adolescentes e forçar uma saída com intuito de fugir. Normalmente, isso ocorre quando os agentes não observam os procedimentos mínimos de segurança. Uma vez percebida a vulnerabilidade pelos internos, estes aproveitam a abertura de portas ou portões para evadirse da Unidade.
} 
desconforto para o professor, promovia a desatenção dos alunos e ocasionava a paralisação das atividades.

\section{CONSIDERAÇÕES FINAIS}

Analisando as condições do Centro Socioeducativo Santa Juliana, observou-se que existem vários fatores que dificultam o processo socioeducativo dos adolescentes e jovens internados. O ideal seria que o próprio Estado ou Ministério Público intervisse e desativasse o aludido Centro, dadas às péssimas condições de habitabilidade e de superlotação. Contudo, seria necessária a construção de, pelo menos, três novas unidades para comportar o contingente atual de socioeducandos, o que demandaria, também, a contratação de novos profissionais.

$\mathrm{Na}$ impossibilidade de construir, a curto prazo, novos espaços para realocar os internos, outra alternativa menos onerosa para o Estado seria implementar uma reforma de manutenção e higiene dos espaços de convivência, visando sanar os problemas estruturais que causam a insalubridade do ambiente, ao mesmo tempo em que se poderia buscar alternativas junto ao Juizado para tentar adequar o número de internos ao de vagas, diante da quantidade de adolescentes e jovens privados de liberdade fora dos critérios estabelecidos no artigo 122 do Estatuto da Criança e do Adolescente.

Além das possibilidades supracitadas, é necessário realizar capacitação de alinhamento conceitual das diretrizes e parâmetros do atendimento socioeducativo para toda equipe do CSSJ, momento de escuta e de intervenção, na perspectiva de sanar conflitos interpessoais e proporcionar condições de aperfeiçoamento técnico. Com isso, busca-se estabelecer uma conduta profissional consciente dos desafios e favorável à construção de uma identidade coletiva.

Somado a isso, é imprescindível construir a proposta pedagógica do programa de internação, priorizando um atendimento com foco no desenvolvimento pessoal e social dos adolescentes e jovens assistidos pelo CSSJ, ao passo que os procedimentos de segurança precisam ser redefinidos. Para tanto, é importante que haja um alinhamento entre os procedimentos de segurança e as ações sociopedagógicas, para tornar possível o funcionamento e a organização de uma rotina institucional, verdadeiramente, socioeducativa.

Em relação à escolarização, é salutar o esforço da equipe pedagógica em realizar um trabalho de qualidade em prol dos alunos que frequentam a escola. Contudo, esse esforço torna-se pouco eficiente devido às condições em que esse processo de ensino e aprendizagem é realizado. A falta de estrutura e a não priorização dada pelas instituições gestoras (ISE e SEE) a essa política básica, prejudica sobremaneira o retorno social dos adolescentes e jovens.

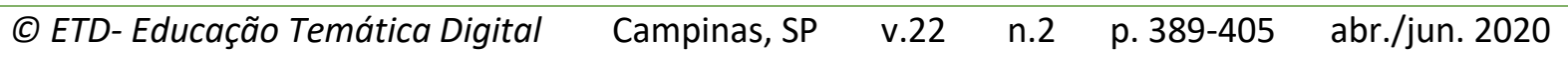


Destarte, o maior prejuízo é daqueles que, por algum motivo, não conseguiram ingressar na escola e tiveram seu direito à educação negligenciado por quem tem o dever de garantir esse direito. Então, não há como esperar outro resultado dessa socioeducação, senão o retorno social de adolescentes e jovens cada vez mais violentos, reincidindo até tornar-se imputáveis e migrarem para o sistema prisional.

\section{REFERÊNCIAS}

ACRE. Secretaria de Estado de Cidadania e Assistência Social. SECIAS em Revista. Rio Branco, 2006. (2006).

ACRE. Secretaria de Estado de Cidadania e Assistência Social. Lei no 2.111, de 31 de dezembro de 2008. Cria o Instituto Socioeducativo do Estado do Acre. Assembleia Legislativa do Estado do Acre. Rio Branco, AC, 22 set. 2014. Disponível em: http://www.al.ac.leg.br/leis/wp-content/uploads/2014/09/Lei2111.pdf. Acesso em: 11 jul. 2018. (2008).

ACRE. Secretaria de Estado de Cidadania e Assistência Social. Instrução Normativa $\mathbf{n}^{\circ}$ 001, de 01 de agosto de 2009. Institui o Regulamento Disciplinar no âmbito das atividades internas dos Centros Socioeducativos do Estado Acre. Diário Oficial do Estado do Acre. Rio Branco, AC, 02 jun. 2010. Disponível em: shorturl.at/dry27. Acesso em: 11 jul. 2018. (2009).

ACRE. Secretaria de Estado de Cidadania e Assistência Social. Instrução Normativa $\mathbf{n}^{\circ} \mathbf{0 2}$, de 25 de outubro de 2010. Dispõe sobre a regulamentação do atendimento técnico aos adolescentes em cumprimento de medidas socioeducativas. Diário Oficial do Estado do Acre. Rio Branco, AC, 27 out. 2010. Disponível em: encurtador.com.br/hzDIW - (2010a).

ACRE. Secretaria de Estado de Cidadania e Assistência Social. Portaria no 084, de 25 de outubro de 2010. Dispõe sobre a nomenclatura e destinação das Unidades Operacionais de Execução de Medidas Socioeducativas. Diário Oficial do Estado do Acre. Rio Branco, AC, 12 set. 2014. Disponível em: http://diario.ac.gov.br/download.php? . Acesso em: 11 jul. 2018. (2010b).

ACRE. Secretaria de Estado de Cidadania e Assistência Social. Portaria no 1.646, de 04 de maio de 2011: Autoriza o funcionamento do Ensino Fundamental, Médio e EJA na Escola Darquinho. (2011).

ACRE. Secretaria de Estado de Cidadania e Assistência Social. Instrução Normativa $\mathbf{n}^{\circ} \mathbf{0 1}$, de 29 de março de 2012. Dispõe sobre a estrutura organizacional das Unidades Operacionais de execução das medidas socioeducativas. Diário Oficial do Estado do Acre. Rio Branco, AC, 30 mar. 2012. Disponível em: shorturl.at/iBFO7. Acesso em: 11 jul. 2018. (2012).

ACRE. Secretaria de Estado de Cidadania e Assistência Social. Portaria no 203 de 11 de dezembro de 2013: estabelece a composição de vagas nas Unidades Socioeducativas de Internação. Disponível em: encurtador.com.br/klHY9. Acesso em: 11 jun. 2018. (2013).

(C) ETD-Educação Temática Digital Campinas, SP $\quad$ v.22 $\quad$ n.2 $\quad$ p. 389-405 abr./jun. 2020 
ACRE. Secretaria de Estado de Cidadania e Assistência Social. Portaria no 143, de 11 de setembro de 2014. Altera a Portaria no 33 de 15 de fevereiro de 2013. Dispõe sobre a alteração de nomenclaturas e destinação das Unidades Operacionais de execução de medidas socioeducativas. Diário Oficial do Estado do Acre. Rio Branco, AC, 12 set. 2014. Disponível em: shorturl.at/cgHP6. Acesso em: 11 jul. 2018. (2014a).

ACRE. Secretaria de Estado de Cidadania e Assistência Social. Resolução CEE/AC no 267/2014. Dispõe sobre a oferta de Educação Básica (Ensino Fundamental e Médio) para aluno em atendimento socioeducativo. Diário Oficial do Estado do Acre. Rio Branco, AC, 04 fev. 2015. (2014b).

BRASIL. Código de Menores de 1979. Lei $\mathrm{n} \cong 6.697$, de 10 de outubro de 1979. Disponível em: http://www.planalto.gov.br/ccivil 03/LEIS/1970-1979/L6697.htm Acesso em: 15 nov. 2018. (1979).

BRASIL. Constituição da República Federativa do Brasil de 1988. Disponível em: https://www.planalto.gov.br/ccivil 03/constituicao/constituicao.htm (1988). Acesso em: 15 nov. 2018. (1988).

BRASIL. Estatuto da criança e do adolescente: Lei no 8.069, de 13 de julho de 1990.

Disponível em: https://www.planalto.gov.br/ccivil 03/leis/L8069.htm. (1990) Acesso em: 15 nov. 2018. (1990).

BRASIL. Lei de Diretrizes e Bases da Educação Nacional: Lei no 9.394, de 20 de dezembro de 1996. Disponível em: https://www.planalto.gov.br/ccivil 03/Leis/L9394.htm. Acesso em: 15 nov. 2018. (1996).

BRASIL. Sistema nacional de atendimento socioeducativo (SINASE): Resolução n 119, de 11 de dezembro de 2006. Brasília: SEDH-PR/CONANDA, 2006. (2006).

BRASIL. Lei no 12.594, de 18 de janeiro de 2012. Disponível em: http://www.planalto. gov.br/ccivil 03/ ato2011-2014/2012/lei/l12594.htm. (2012) Acesso em: 15 nov. 2018. (2012).

BRASIL. Lei no 12.852, de 5 de agosto de 2013. Disponível em: http://www.planalto.gov.br/ ccivil 03/ Ato2011-2014/2013/Lei/L12852.htm. (2012) Acesso em: 15 nov. 2018. (2013).

BRASIL. Presidência da República. Secretaria de Direitos Humanos Levantamento Anual dos/as Adolescentes em Conflito com a Lei - 2012. Curitiba, PR: SEDH/PR, 2015. (2015).

BRASIL. Presidência da República. Secretaria de Direitos Humanos. Levantamento Anual SINASE 2016: privação e restrição de liberdade. Brasília: SEDH/PR, 2018. (2018).

BRASIL. Observatório Nacional dos Direitos da Criança e do Adolescente (OBS). SIPIA. Disponível em: https://www.sipia.gov.br/. Acesso em: 13 jan. 2019. (2019). 
COSTA, Antônio Carlos G. da. O ECA e outras políticas sociais, 2008. Disponível em: http://www.promenino.org.br/noticias/especiais/o-eca-e-outras-politicas-sociais. Acesso em: 21 out. 2018. (2008).

LIMA, Cristiane Sasso de; MIOTO, Regina Célia Tamaso; DAL PRÁ, Keli Regina. A documentação no cotidiano da intervenção dos assistentes sociais: algumas considerações acerca do diário de campo. In: Revista Textos \& Contextos. Porto Alegre v. 6 n. 1 p. 93-104. jan./jun. 2007. Disponível em: http://revistaseletronicas.pucrs.br/fass/ojs/ index.php/fass/article/view/1048/3234. Acesso em: 18 out. 2019. (2007).

SARAIVA, A. M. A. Distorção idade-série. In: OLIVEIRA, D. A.; DUARTE, A. M. C.; VIEIRA, L. M. F. Dicionário: trabalho, profissão e condição docente. Belo Horizonte: UFMG/Faculdade de Educação, 2010. CDROM. Disponível em: http://www.gestrado.net.br/pdf/237.pdf. Acesso em: 28 maio 2018.

ZANELLA, Maria Nilvane. O papel do pedagogo na socioeducação: a educação escolar como possibilidade de emancipação política de adolescentes em conflito com a lei In: CONCEIÇÃO, Willian Lazaretti (Org.). Atendimento socioeducativo: atores e atrizes de um cenário em movimento, Jundiaí, SP: Paco Editorial, 2016, p. 167-183. (2016).

Revisão Gramatical realizada por: Sergio da Silva Santos.

E-mail: sergiodudusantos@gmail.com 